\title{
Peculiar points in the phase diagram of the water-alcohol solutions
}

\author{
V.E. Chechko ${ }^{1}$, V.Ya. Gotsulsky ${ }^{1}$, M.P. Malomuzh ${ }^{2}$ \\ 1 Scientific-Research Institute of Physics, Odessa National University, 2 Dvoryanska St., Odessa, 65026, Ukraine \\ 2 Department of Theoretical Physics, Odessa National University, 2 Dvoryasnka St., Odessa, 65026, Ukraine
}

Received January 9, 2013, in final form April 2, 2013

\begin{abstract}
The work is devoted to the investigation of nontrivial behavior of dilute water-alcohol solutions. The temperature and concentration dependencies of the contraction for aqueous solutions of ethanol and methanol are analyzed. The existence of a specific point, the so-called peculiar point, was established. It is shown that wateralcohol solutions of different types obey the principle of corresponding states if temperature and volume fraction are used as principal coordinates. In this case, the concentration of the peculiar point for different solutions is close to $x_{v}=0.28$. Several predictions are made.
\end{abstract}

Key words: water-alcohol solutions, contraction, peculiar point

PACS: $01.55 .+b$

\section{Introduction}

During long time the opinion that properties of dilute molecular solutions are close to ideal ones [1-3] was widespread. The situation essentially changed following the first experiments on molecular light scattering (MLS) in dilute water-alcohol solutions (see [4-10]). It was shown that an anomalous increase of the integral intensity for aqueous solutions of ethanol, tertiary butanol, glycerol and others is observed if the molar concentration approaches $x_{M}=0.04 \div 0.09$ and temperature is within some interval characteristic of each solution. In addition, the intensity increases more than ten times. In subsequent years, the similar anomalies were observed for many other water-alcohol solutions.

Here, it should be noted that anomalous MLS is in fact observed at approaching some line $L_{\mathrm{p}}$ in the plane $\left(T, x_{m}\right)$. The point $x_{\mathrm{p}}$ on this line for which the maximum of the MLS is observed was named the peculiar point. Hereafter we will refer to the corresponding line of relative maxima as the peculiar line.

The important fact for water-glycerol solutions was established in [11] where it was shown that the correlation length of the concentration fluctuations increases up to $70 \AA$ at approaching the peculiar point. In this case, the absolute maximum for the intensity for MLS is observed for $T_{\mathrm{p}} \approx 303 \mathrm{~K}$ and $x_{\mathrm{p}} \approx 0.04$. Such a behavior of the correlation length reflects the existence of instability points for the concentration fluctuations.

In [12, 13], the peculiar line was identified with the position of the pseudo-spinodal for water-alcohol solutions, that separates the regions with different cluster structures. These clusters are formed due to H-bonds connecting water and alcohol molecules stronger than between molecules of the same kind [14]. In particular, according to [12], clusters formed on the left of the pseudo-spinodal consist of two glycerol molecules and ten molecules of water. An analogous situation is also characteristic of waterethanol solutions [15].

The change of the water-alcohol structure near the peculiar line is also manifest in the behavior of the adiabatic compressibility [16, 17], the heat capacity [18, 19], diffusion of components [20] and other phenomena. However, all these manifestations were only fragmentarily investigated.

In the present paper, we focus on the analysis of temperature and concentration dependencies of the contraction for aqueous solutions of ethanol and methanol. We want to establish the applicability of 
the principle of corresponding states to the description of contraction in water-alcohol solutions. Some predictions will be made on this basis.

\section{Contraction and adiabatic compressibility for water-alcohol}

By definition, the contraction of binary solution is equal to:

$$
\varphi(x, T)=\frac{V_{12}}{V_{1}+V_{2}}-1,
$$

where $V_{i}, i=1,2$ are the initial volumes of components, $V_{12}$ is the total volume of their mixture. It is clear that the contraction is the simplest thermodynamic characteristic of binary solutions. Its behavior for aqueous solutions of ethanol and methanol is presented in figure 1 and figure 2

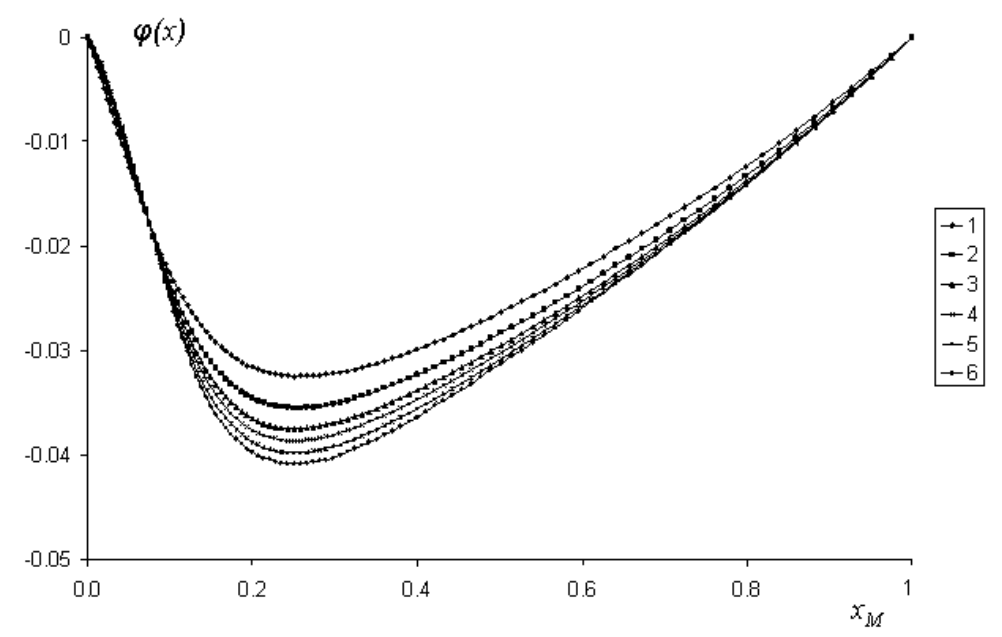

Figure 1. The concentration dependencies of $\varphi(x)$ for water-ethanol solutions at different temperatures: $1-40^{\circ} \mathrm{C}, 2-20^{\circ} \mathrm{C}, 3-10^{\circ} \mathrm{C}, 4-5^{\circ} \mathrm{C}, 5-0^{\circ} \mathrm{C}, 6--5^{\circ} \mathrm{C}$.

First, the contraction of water-ethanol solutions was investigated by Mendeleev about 130 years ago [21]. He established the existence of three peculiar points: $x_{\mathrm{M}}^{(\mathrm{P})} \approx 0.077,0.25,0.75$, which were identified with the intersection of straight lines used to approximate the derivative $\left.\frac{\partial \varphi}{\partial x}\right|_{T}$ in the concentration intervals: $(0,0.07),(0.1,0.2),(0.3,0.7),(0.8,1)$. However, Mendeleev investigated the behavior of the contraction only for room temperatures. Experimental data for $V_{12}$ for other temperatures were obtained much later [22]. This seems very strange, but a systematic study of $\varphi(x)$ was not even carried out for typical water-alcohol solutions.

As we see, the contraction curves for both aqueous solutions of ethanol and methanol have the following peculiarities:

a) the signs of the contractions are negative;

b) all curves have minima near $x_{\min }^{(\mathrm{et})}=0.23$ and $x_{\min }^{(\mathrm{met})}=0.39$;

c) the curves corresponding to different temperatures intersect near $x_{\mathrm{p}}^{(\mathrm{et})}=0.077$ and $x_{\mathrm{p}}^{(\mathrm{met})}=0.12$ (see figure 3).

A detailed consideration of the contraction for water-ethanol solution is given in [24]. Here, we will only analyze the most characteristic properties of the contraction in the vicinity of their peculiar points in aqueous solutions of alcohol. 


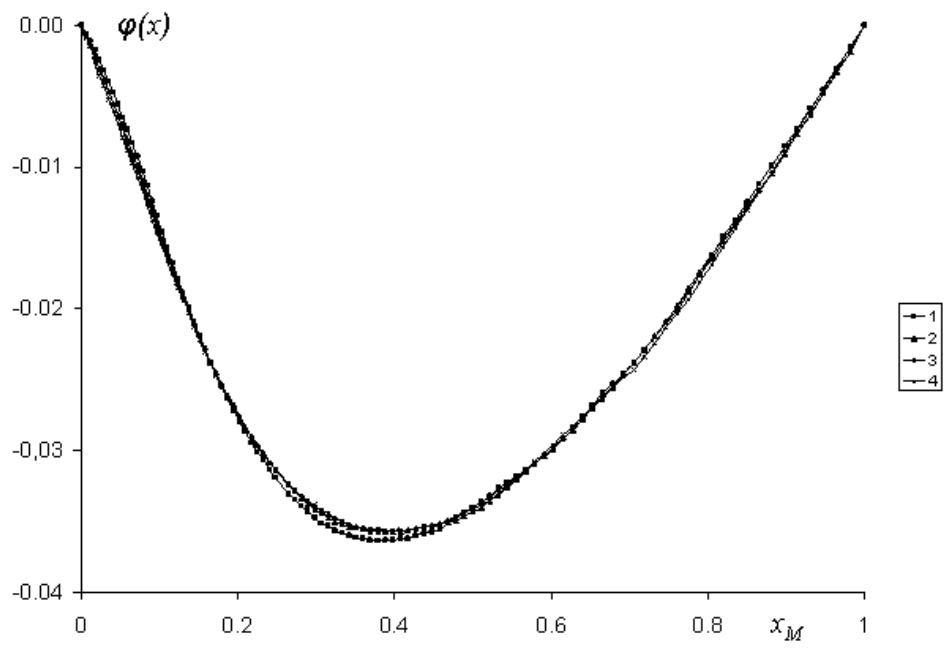

Figure 2. The concentration dependencies of $\varphi(x)$ for water-methanol solutions at different temperatures [23]: $1-0^{\circ} \mathrm{C}, 2-10^{\circ} \mathrm{C}, 3-15.6^{\circ} \mathrm{C}, 4-20^{\circ} \mathrm{C}$.

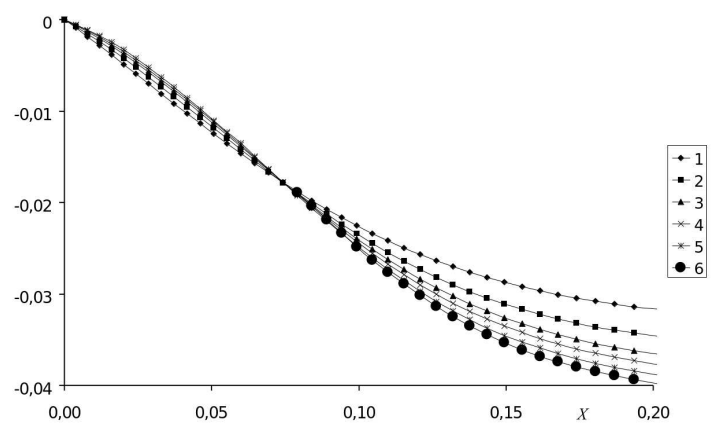

(a) Ethanol

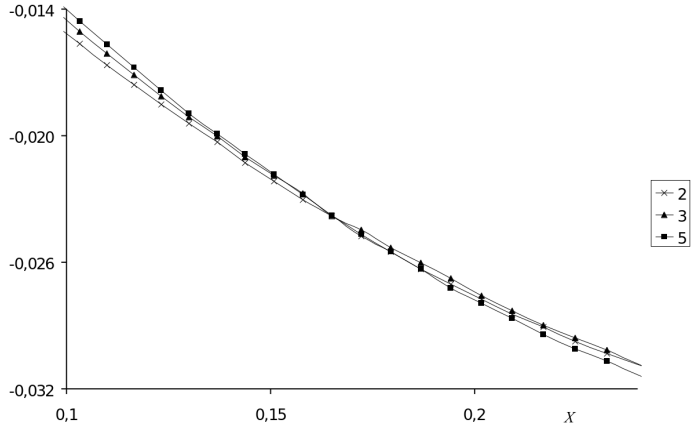

(b) Methanol

Figure 3. The vicinities of peculiar points for aqueous solutions of ethanol and methanol at different temperatures: $1-40^{\circ} \mathrm{C}, 2-20^{\circ} \mathrm{C}, 3-10^{\circ} \mathrm{C}, 4-5^{\circ} \mathrm{C}, 5-0^{\circ} \mathrm{C}, 6--5^{\circ} \mathrm{C}$.

The position of the peculiar point $x_{\mathrm{p}}^{(\mathrm{et})}=0.077$ for water-ethanol solution practically coincides with that, registered in the MLS experiments [25] [ $x_{\mathrm{p}}^{\text {(et) }}(\mathrm{MLS})=0.077$ ]. Unfortunately, there are no corresponding data for aqueous solutions of methanol. Moreover, only for water-ethanol solutions the existence of the peculiar point is certified with the help of contraction and the MLS, i.e., by thermodynamic and dynamic methods.

On the other hand, the existence of the peculiar point in water-alcohol solutions is also supported by caloric measurements. So, the specific behavior of the heat capacity at approaching the peculiar points was observed in [19] for aqueous solutions of TBA (tertiary butanol alcohol). The heat capacity of these solutions is characterized by sharp peaks similar to those near the critical points. However, the height of peaks near the peculiar point remains finite.

The strong increase of the MSL intensity near the peculiar point means that optical homogeneity of water-alcohol solutions is violated by large scale fluctuations, accessible for observation in the visible light range. This fact is immediately supported by data of correlation spectroscopy [11], according to which the characteristic size of heterogeneities reaches $70 \AA$. From the general point of view, an anomalous increase of fluctuations is connected with the instability of water-alcohol solutions near their peculiar points. However, this instability cannot be connected with delamination of these solutions. Usually, their 
delamination is observed for $0.3<x_{M}<0.5$ and sometimes for $x_{M}$ close to 0.1 . Therefore, the appearance of instability should be connected with structural transformations in water-alcohol solutions.

Experimental data on the adiabatic compressibility $\beta_{\mathrm{S}}$ for aqueous solutions of $\gamma$-picoline and acetone in [16, 17] provide us with the important additional information on the physical nature of peculiar points. The quantity $\beta_{\mathrm{S}}$ is naturally connected with the adiabatic sound velocity: $\beta_{\mathrm{S}}=1 /\left(\rho c_{\mathrm{S}}^{2}\right)$, where $c_{\mathrm{S}}=\omega_{\mathrm{MB}} / k$ and $\omega_{\mathrm{MB}}$ is the frequency of the Mandelshtam-Brilluoin components ( $\rho$ is the mass density and $k$ is the transfer wave vector).

All these facts allow us to conclude that (i) dilute water-alcohol solutions can be considered as ensembles of elementary clusters. They are formed by H-bonding between water and alcohol molecules, which is stronger than the interaction between molecules of the same components; (ii) elementary clusters form a percolation cluster when $x \rightarrow x_{\mathrm{p}}$. Near $x_{\mathrm{p}}$, they begin to overlap and are destroyed; (iii) the character of clusterization is different on the right of $x_{\mathrm{p}}$.

In other words, structural transformations in the vicinity of $x_{\mathrm{p}}$ can be qualified as a smeared phase transition between different cluster structures.

Some details of the clusterization in aqueous solutions of glycerol-ethanol and $\gamma$-picoline are discussed in [12, 13, 15]. In these papers it was shown that peculiar points of these solutions are located on pseudo-spinodals separating the states of solutions with different character of clusterization.

\section{Principle of corresponding states for the description of contraction}

The usage of molar concentration in figures 1-5 does not allow us to display the role of molecular parameters, such as an inherent molecular volume and the degree of nonsphericity, in the formation of the contraction. However, exactly these parameters essentially effect the structure and size of elementary clusters in low concentration region. In turn, this also effects the value of molar concentration, which corresponds to the percolation threshold.

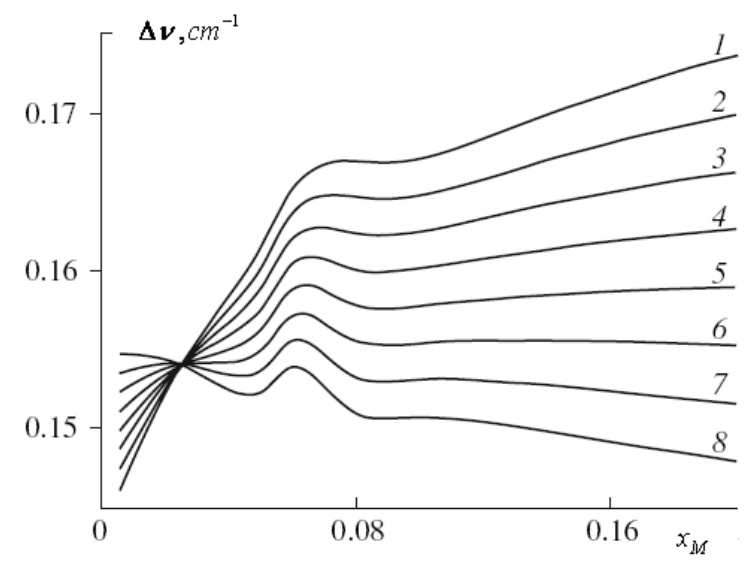

Figure 4. Isotherms of the concentration dependency for the Mandelshtam-Brilluoin components $[\Delta v=$ $\omega_{\mathrm{MB}} /(2 \pi c), c$ is the vacuum light velocity] in aqueous solutions of $\gamma$-picoline: $1-10^{\circ} \mathrm{C}, 2-20^{\circ} \mathrm{C}, 3-$ $30^{\circ} \mathrm{C}, 4-40^{\circ} \mathrm{C}, 5-50^{\circ} \mathrm{C}, 6-60^{\circ} \mathrm{C}, 7-70^{\circ} \mathrm{C}, 8-80^{\circ} \mathrm{C}$ [16].

From this point of view, it follows that elementary clusters in methanol and ethanol should (i) be similar since they correspond to the components forming only one H-bond between water and alcohol molecules and (ii) have different volumes, since molecules of methanol and ethanol have noticeably different molecular volumes. We expect that the ratio $x_{\mathrm{p}}^{(\mathrm{et})} / x_{\mathrm{p}}^{(\mathrm{met})}$ reduces to the simplest estimate:

$$
\frac{x_{\mathrm{p}}^{(\mathrm{et})}}{x_{\mathrm{p}}^{(\mathrm{met})}} \Rightarrow \frac{v_{m}^{(\mathrm{met})}}{v_{m}^{(\mathrm{et})}} \approx 0.7 \text {. }
$$




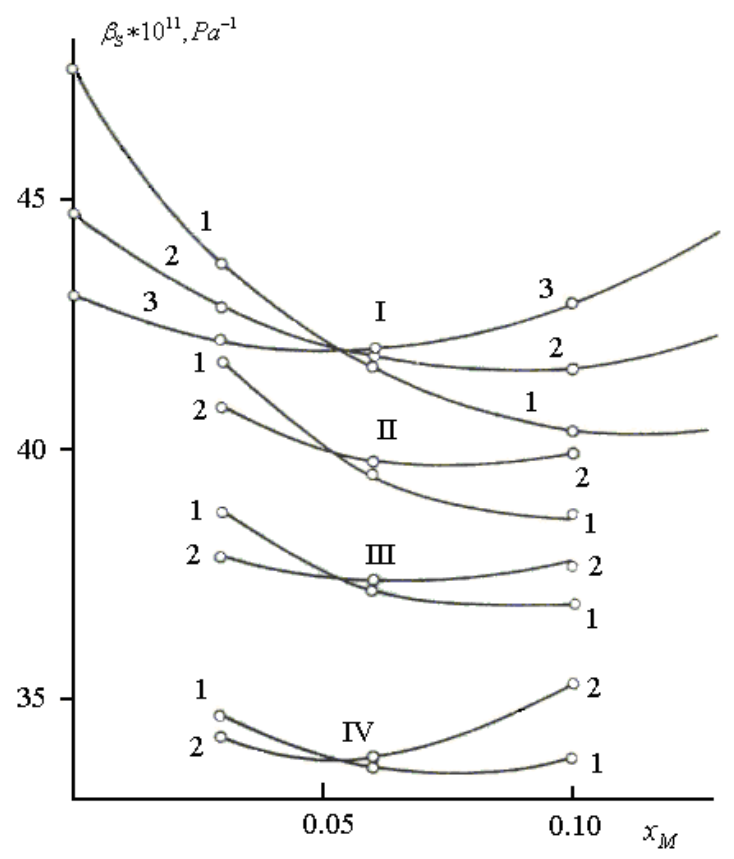

Figure 5. The adiabatic compressibility, $\beta_{\mathrm{S}}$, for aqueous solutions of acetone as a function of concentration for different temperatures $\left(1-10^{\circ} \mathrm{C}, 2-25^{\circ} \mathrm{C}, 3-40^{\circ} \mathrm{C}\right.$ ) and sodium chloride concentrations (I -0 , II -0.4 , III - 1.0, IV - 2.0) [17].

Taking the experimental values of $x_{\mathrm{p}}^{(\mathrm{et})}$ and $x_{\mathrm{p}}^{(\mathrm{met})}$, we find $x_{\mathrm{p}}^{(\mathrm{et})} / x_{\mathrm{p}}^{(\mathrm{met})} \approx 0.72$, i.e., the agreement between the ratios $x_{\mathrm{p}}^{(\mathrm{et})} / x_{\mathrm{p}}^{(\mathrm{met})}$ and $v_{m}^{(\mathrm{met})} / v_{m}^{(\mathrm{et})}$ is practically full.

This example shows that the volume fraction $x_{v}$, defined as

$$
x_{v}=\frac{n_{2} v_{2}}{n_{1} v_{1}+n_{2} v_{2}} \Rightarrow \frac{x_{\mathrm{M}} v_{2}}{\left(1-x_{\mathrm{M}}\right) v_{1}+x_{\mathrm{M}} v_{2}},
$$

is a more natural coordinate for the description of contraction than the molar concentration: $x_{\mathrm{M}}=$ $n_{2} /\left(n_{1}+n_{2}\right)$. This conjecture is supported by figure 6

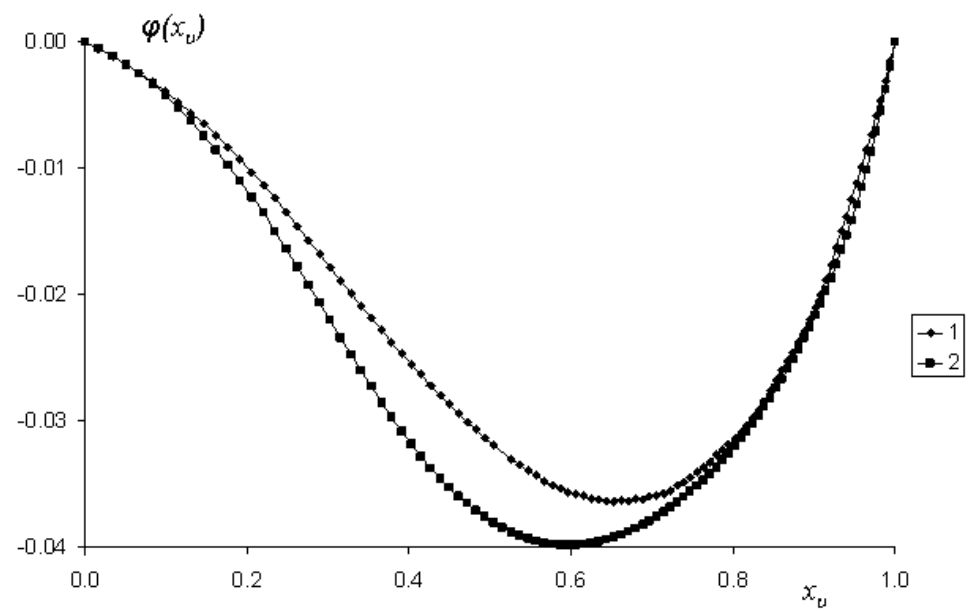

Figure 6. The contraction of water-ethanol (1) and water-methanol (2) solutions as a function of the volume fraction at $0^{\circ} \mathrm{C}$. 
For other temperatures, the agreement between methanol and ethanol curves is analogous to that in figure 6, i.e., curves practically coincide for $0<x<0.2$ and $0.65<x<1.0$.

These facts allow us to conclude that the contraction behavior for aqueous solutions of alcohols, for which only one $\mathrm{H}$-bond forms between water and alcohol molecules, is approximately consistent with the principle of corresponding states. In addition, the volume fraction and temperature are natural variables for the description of the contraction behavior. Maximal values of deviations from some universal curve do not exceed $10 \%$.

For low concentrations $x_{v}=x_{\mathrm{M}} v_{1} / v_{2}$, and the peculiar point is determined by the coordinate:

$$
x_{v}^{(\mathrm{P})}=x_{\mathrm{M}}^{(\mathrm{P})} \frac{v_{\mathrm{a}}}{v_{\mathrm{w}}}+\cdots .
$$

If the ratio $v_{\mathrm{a}} / v_{\mathrm{b}}$ is much larger than unity, $x_{v}^{(\mathrm{P})}$ is a nonlinear function of $x_{\mathrm{M}}^{(\mathrm{P})}$ as it is demonstrated in figure 7. In particular, for the ratio $x_{v}^{(\mathrm{P})}(\mathrm{met}) / x_{v}^{(\mathrm{P})}(\mathrm{et})$, we obtain:

$$
\frac{x_{v}^{(\mathrm{P})}(\mathrm{met})}{x_{v}^{(\mathrm{P})}(\mathrm{et})} \approx \frac{x_{\mathrm{M}}^{(\mathrm{P})}(\mathrm{met})}{x_{\mathrm{M}}^{(\mathrm{P})}(\mathrm{et})} \frac{v_{\mathrm{met}}}{v_{\mathrm{et}}} \frac{1+x_{\mathrm{M}}^{(\mathrm{P})}(\mathrm{et})\left(\frac{v_{\mathrm{et}}}{v_{\mathrm{w}}}-1\right)}{1+x_{\mathrm{M}}^{(\mathrm{P})}(\mathrm{met})\left(\frac{v_{\mathrm{met}}}{v_{\mathrm{w}}}-1\right)} .
$$

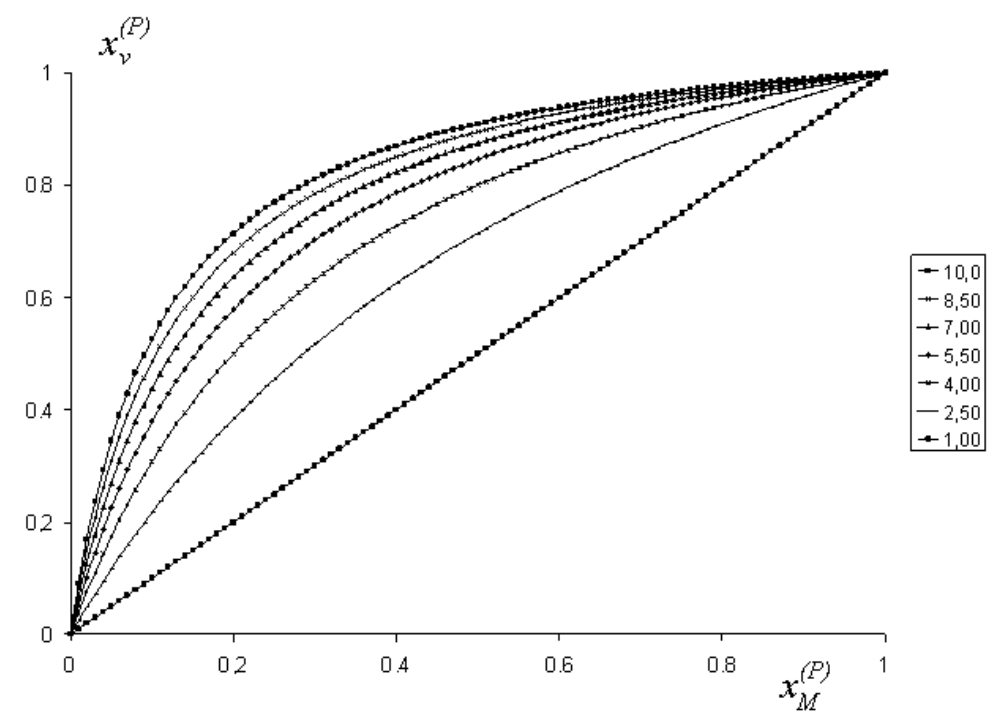

Figure 7. The interconnection between $x_{v}^{(\mathrm{P})}$ and $x_{\mathrm{M}}^{(\mathrm{P})}$ according to (2) for different values of the ratio $v_{\mathrm{w}} / v_{\mathrm{a}}$.

From here and (1) it follows that

$$
\frac{x_{v}^{(\mathrm{P})}(\mathrm{met})}{x_{v}^{(\mathrm{P})}(\mathrm{et})} \approx 1 .
$$

Thus, the volume fractions of methanol and ethanol at their peculiar points are the same and we can write

$$
x_{v}^{(\mathrm{P})}(\mathrm{et}) \approx x_{v}^{(\mathrm{P})}(\mathrm{met}) \approx 0.28 .
$$

In accordance with our reasoning, this is a characteristic volume fraction of alcohol that stimulates the structural reconstruction in water-alcohol solution. Therefore, we expect that

$$
x_{v}^{(\mathrm{P})}(\mathrm{alc}) \approx 0.28
$$


for those water-alcohol solutions in which only one H-bond is formed between water and alcohol molecules.

The corresponding value for the molar concentration is equal to:

$$
x_{\mathrm{M}}^{(\mathrm{P})}(\mathrm{alc})=0.28 \frac{v_{\mathrm{w}}}{v_{\mathrm{alc}}} \frac{1}{1-0.28\left(1-\frac{v_{\mathrm{w}}}{v_{\mathrm{alc}}}\right)} .
$$

In order to find the ratio $v_{\mathrm{w}} / v_{\mathrm{alc}}$, we will use the fact that the effective molecular volume for liquids is close to the corresponding fraction volume:

$$
v_{i}=\frac{1}{n_{i}} \approx \frac{m_{i}}{\rho_{i}}, \quad i=\mathrm{w}, \text { alc },
$$

where $n_{i}$ and $\rho_{i}$ are the number and mass densities, respectively, and $m_{i}$ is the molecular mass. Then,

$$
\frac{v_{\mathrm{w}}}{v_{\mathrm{alc}}} \approx \frac{m_{\mathrm{w}}}{m_{\mathrm{alc}}} \cdot \frac{\rho_{\mathrm{alc}}}{\rho_{\mathrm{w}}} .
$$

In particular, for TBA $\left(\rho=0.7887 \frac{g}{\mathrm{~cm}^{3}}, \mu=74.12 \frac{g}{\mathrm{~mol}}\right)$ we obtain

$$
x_{\mathrm{M}}^{(\mathrm{P})}(\mathrm{TBA}) \approx 0.069 \text {. }
$$

\section{Discussion of the results obtained}

As was noted above, the structural transformations in water-alcohol solutions near their peculiar points also manifest themselves in the molecular light scattering experiments and in other phenomena. The positions of the peculiar points, determined by different methods, are presented in table 1. It is taken into account that the MLS intensity usually has maximums for two concentrations: (i) near $x_{\mathrm{M}}$ (alc) $0.1 \div 0.5$, which corresponds to the standard delamination of solution and (ii) near $x_{\mathrm{M}}$ (alc) $\sim 0.03 \div 0.08$,

\begin{tabular}{|c|c|c|c|c|}
\hline $\begin{array}{c}\text { Aqueous solutions } \\
\text { of some substances } \\
\text { (W-substances) }\end{array}$ & $\begin{array}{c}\text { Intensity maximum } \\
\text { in low } \\
\text { concentrations } \\
\text { region }\end{array}$ & $\begin{array}{c}\text { Intensity maximum } \\
\text { in middle } \\
\text { concentrations } \\
\text { region }\end{array}$ & $\begin{array}{l}\text { Inversion point } \\
\text { for the velocity } \\
\text { sound }\end{array}$ & $\begin{array}{l}\text { Minimum of } \\
\text { the partial } \\
\text { molar } \\
\text { volume }\end{array}$ \\
\hline W-ethanol & $0.09\left(T=20^{\circ} \mathrm{C}\right)[25]$ & Indistinct [25] & 0.068 [28] & 0.07 [29] \\
\hline W-methanol & $0.12\left(T=20^{\circ} \mathrm{C}\right)[25]$ & & & \\
\hline $\begin{array}{l}\text { W-isopropyl } \\
\text { alcohol }\end{array}$ & $\begin{array}{l}0.06\left(T=20^{\circ} \mathrm{C}\right)[25] \\
0.08[8]\end{array}$ & Indistinct [25] & 0.04 [28] & 0.06 [29] \\
\hline $\begin{array}{l}\text { W-n-propyl } \\
\text { alcohol }\end{array}$ & $0.05\left(T=20^{\circ} \mathrm{C}\right)$ & 0.15 [25] & $0.05[\overline{9}]$ & $0.045[29]$ \\
\hline $\begin{array}{l}\text { W-tertiary } \\
\text { butyl alcohol }\end{array}$ & $0.03[25]$ & - & 0.032 [28] & - \\
\hline W-glycerol & $0.04\left(T=10^{\circ} \mathrm{C}\right)[11]$ & - & - & - \\
\hline $\mathrm{W}-\beta$-picolin & 0.05 [27] & - & - & - \\
\hline W-acetone & 0.055 [29] & 0.1 [9] & 0.062 [28] & $0.07[29]$ \\
\hline
\end{tabular}
which corresponds to structural transformations in the vicinity of its peculiar point. These maxima are only observed within some temperature intervals.

Table 1. Manifestations of the peculiar point in the MLS and other experiments.

Positions of the peculiar points, calculated for the same water-alcohol solutions according to (7) and (8), are presented in table 2

On the whole, we find a quite satisfactory agreement between experimental and calculated data. For the majority of water-alcohol solutions, the difference between experimental and calculated data does 
Table 2. Positions of the peculiar points determined according to (7) and (8).

\begin{tabular}{|l|c|}
\hline $\begin{array}{c}\text { Aqueous solutions of some } \\
\text { substances collected in the table 1 }\end{array}$ & $\begin{array}{c}\text { Positions of the peculiar points } \\
\text { according to (7) and (8) }\end{array}$ \\
\hline \hline W-ethanol & 0.09 \\
\hline W-methanol & 0.12 \\
\hline W-isopropyl alcohol & 0.08 \\
\hline W-n-propyl alcohol & 0.08 \\
\hline W-tertiary butyl alcohol & 0.066 \\
\hline W-glycerol & 0.084 \\
\hline W- $\beta$-picolin & 0.064 \\
\hline W-acetone & 0.083 \\
\hline
\end{tabular}

not exceed the width of the interval for the experimental error. Among alcohols that form only one $\mathrm{H}-$ bond with water molecules, the calculated value of $x_{\mathrm{M}}^{(\mathrm{P})}$ exceeds approximately twice the corresponding experimental value only for tertiary butyl alcohol. A considerable deviation of the calculated value for $x_{\mathrm{M}}^{(\mathrm{P})}$ from experimental one is also observed for water-glycerol solution. However, a glycerol molecule can form three H-bonds with water molecules. Thus, it seems doubtful that water-glycerol solutions belong to the water-ethanol similarity class.

Here, it is interesting to note that the Russian vodka and Ukrainian horilka are aqueous solutions of ethanol having concentration of 40 volume percent. This is more than the concentration for the peculiar point $\left[x_{v}^{(\mathrm{P})}(\mathrm{et}) \approx 0.28\right]$ but it is smaller in comparison with the concentration $x_{v}^{(\mathrm{min})}(\mathrm{et}) \approx 0.55$ characteristic of the minimum of contraction (see figure 1 and figure 7). Such a volume fraction of ethanol is more characteristic of different kinds of cognacs.

It should be noted that Mendeleev was the first to relate the appearance of peculiar points to the formation of molecular complexes in water-ethanol solutions. Thus, he related the low concentration peculiar point at $x_{\mathrm{M}}(\mathrm{et}) \approx 0.077$ for water-ethanol solution to the formation of a complex consisting of one molecule of ethanol and 12 molecules of water. The second peculiarity at $x_{M}(e t) \approx 0.23$ corresponds to a complex of 1 ethanol and 3 water molecules (see [21]). In recent years, Mendeleev's fruitful ideas were developed in the works [12, 13, 15, 24, 30, 31].

We want to dedicate this paper to 60-th anniversary of Professor Mychailo Kozlovskii who made essential contribution to the theory of critical phenomena. We hope that nontrivial peculiarities of dilute water-alcohol solutions will also attract his attention.

\section{References}

1. Prigogine I., The Molecular Theory of Solution. North-Holland Publishing Company Amsterdam Interscience publishers, INC., New York, 1957.

2. Smirnova N.A., Molecular Theories of Solutions, Khimiya, Leningrad, 1987 (in Russian).

3. Landau L.D., Lifschitz E.M., Statistical Physics, Part 2, Pergamon Press, Oxford, 1981.

4. Roshchina G.P., In: Critical Phenomena and Fluctuations in Solutions, Publishing House of Acad. Sci. USSR, Moscow, 1960, 109-116 (in Russian).

5. Eskin V.E., Nesterov A.E., Ukr. Fiz. Zh., 1964, 9, No. 2, 540-544 (in Russian).

6. Beer C.W., Jolly D.J., Opt. Commun., 1974, 11, Iss. 2, 150-151; doi 10.1016/0030-4018(74)90205-3

7. Vuks M.F., Light Scattering in Gases, Liquids and Solutions, Leningrag. University Press, Leningrad, 1977 (in Russian).

8. Lanshina L.V., Russ. J. Phys. Chem. A, 1998, 72, No. 7, 1110.

9. Subramanian D., Anisimov M.A., J. Phys. Chem. B, 2011, 115, Iss. 29, 9179-9183; doi 10.1021/jp2041795

10. Chechko V.Eu., Lokotosh T. V., Malomuzh N. P., Zaremba V. G., Gotsulsky V.Ya., J. Phys. Stud., 2003, 7, No. 2, 175183.

11. Chechko V. E., Gotsulskiy V. Ya., Zaremba V.G., J. Mol. Liq., 2003, 105, Iss. 2-3, 211-214; doi 10.1016/S0167-7322(03)00055-2 
12. Malomuzh N.P., Slinchak E.L., Russ. J. Phys. Chem. A, 2007, 81, No. 11, 1777-1782; doi 10.1134/S0036024407110106

13. Malomuzh N.P., Slinchak E.L., Ukr. J. Phys., 2008, 53, No. 10, 966-970.

14. Pimentel G.C., McClellan A.L., The Hydrogen Bond, W.H. Freeman Publishers, San Francisco, 1960.

15. Malomuzh N.P., Pankratov K.N., Slinchak E.L., Ukr. J. Phys. 2008, 53, No. 11, 1080-1085.

16. Dakar G.M., Khakimov P.A, Korikova M.L., J. Phys. Chem., 1992, 66, No. 1, 200 (in Russian).

17. Sabirov L.M., Semenov D.I., Khaĭdarov Kh.S., Opt. Spectrosc., 2008, 105, No. 3, 369-376; doi 10.1134/S0030400X08090087.

18. Anisimov M.A., Esipov V.S., Zaprudskii V.M. , Zaugol'nikova N.S., Ovodov G.I., Ovodova T.M., Seifer A.L., J. Struct. Chem., 1977, 18, No. 5, 663-670; doi 10.1007/BF00746104

19. Anisimov M.A., Critical Phenomena in Liquids and Liquid Crystals, Nauka, Moscow, 1987 (in Russian).

20. Bulavin L., Slisenko V., Vasylkevych O., Kovalyov O., Krotenko V., Korbetskyi E., In: Modern Problems of Molecular Physics, Kyiv National University Publ. House, Kyiv, 2006, 73-78 (in Ukrainian).

21. Mendeleev D.I., Solutions. The series “Classics of Science”, Publishing House of Acad. Sci. USSR, Moscow, 1956 (in Russian).

22. Tables for the determination of ethanol in water-alcohol solution. State Committee of Standards Council of Ministers, Moscow, 1972 (in Russian).

23. CRC Handbook of Chemistry and Physics, 44th ed., 1962, 2582-2584.

24. Gotsulskiy V.Ya., Malomuzh N.P., Chechko V.E., Russ. J. Phys. Chem. A (unpublished).

25. Vuks M.F., Shurupova L.V., Opt. Spectrosc., 1976, 40, No. 1, 154-159 (in Russian).

26. Eskin V.E., Nesterov A.E., Ukr. Fiz. Zh., 1964, 9, No. 2, 540 (in Russian).

27. Endo H., Bull. Chem. Soc. Jpn., 1973, 46, No. 4., 1106-1111; doi 10.1246/bcsj.46.1106

28. Chaban I.A., Sov. Phys. Acoust., 1975, 21, No. 2, 286-293 (in Russian).

29. Tonaka H., Nakanishi K., Touhara H., J. Chem. Phys., 1984, 81, 4065-4073; doi 10.1063/1.448150

30. Atamas A.A., Atamas N.A., Bulavin L.A., J. Mol. Liq., 2005, 120, 15-17; doi 10.1016/j.molliq.2004.07.073

31. Atamas A.A., Atamas N.A., Bulavin L.A., Russ. J. Phys. Chem. A, 2005, 79, No. 8, 1428-1432 (in Russian).

\title{
Особливі точки фазової діаграми водно-спиртових розчинів
}

\author{
Чєчко В.є! 1, Гоцульський В.я!1, Маломуж М.п! 2 \\ 1 Науково-дослідний інститут фізики, Одеський національний університет, Дворянська 2, Одеса, Україна \\ 2 Кафедра теоретичної фізики, Одеський національний університет, Дворянська 2, Одеса, Україна
}

Робота присвячена дослідженню нетривіальної поведінки розбавлених водно-спиртових розчинів. Проаналізовано температурні і концентраційні залежності стиснення водних розчинів етанолу і метанолу. Специфічна поведінка залежностей призводить до існування особливої точки. Показано, що водноспиртові розчини різних типів підкоряються принципу відповідних станів, якщо застосовувати в якості основних координат температуру і об'ємну частку спирту. У цьому випадку особливості різних параметрів спостерігаються в околі концентрацій близьких до $x_{v}=0.28$. Зроблено декілька прогнозів.

Ключові слова: водно-спиртові розчини, контракція, особлива точка 


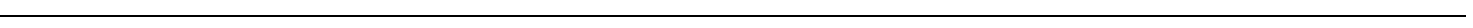

